\title{
HAPPINESS, ECONOMICS AND PUBLIC POLICY: A CRITIQUE
}

\author{
Review article on "Happiness, Economics and Public Policy" \\ by Helen Johns and Paul Ormerod
}

The Institute of Economic Affairs, London, UK, 2007

ISBN: 978025536600 7, 108 pages.

Jan Ott, Erasmus University Rotterdam, the Netherlands; jan.ott@planet.nl

\begin{abstract}
If politicians and their advisers want to promote the well-being or happiness of citizens they have three ways to find out what they should do. (1) They can analyse the behaviour and the decisions of citizens to find out what they want, in other words: they can try to identify their "revealed preferences". This is common practice in economics. (2) They can analyse the "stated preferences" of people as they express them explicitly in inquiries, referenda, polls and elections. (3) They can analyse the conditions that make people happy by comparing the conditions of people at different levels of happiness. Economists, like Helen Johns and Paul Ormerod, have an outspoken preference for the first option and they are sceptical about the third. Their argument is unbalanced because they are too critical about the authenticity and complexity of self-reported happiness and not critical enough about the authenticity and complexity of revealed preferences. Economists should appreciate the comparative advantages and additional value of each option and try to find optimal combinations with synergistic effects. Economists should appreciate happiness research as an option to assess the nature and magnitude of "externalities" within their own discipline.
\end{abstract}

KEY WORDS: revealed preferences, stated preferences, happiness, well-being, externalities

Helen Johns and Paul Ormerod are both economists with a lot of experience in research and consultancy. They are critical of self-reported happiness research and its significance for policy-development. They summarized their objections in a concise, but deeply cutting book. Their criticism is based on the following arguments.

1. Johns and Ormerod observe that average self-reported happiness in nations is insensitive to important developments. We see hardly any change in time-series for average happiness in nations, whilst there have been important developments in variables like Gross National Product (GNP), public expenditure, life-expectancy, violent crime, income-inequality and gender equality (p. 34-38). The absence of any substantial impact of increasing GNP has been extensively discussed in research on happiness, but the lack of any substantial impact of other factors has been seriously neglected.

2. Johns and Ormerod conclude that we face a dilemma: either we conclude that attempting to improve the human lot is futile, or we conclude that self-reported happiness over time is an extremely insensitive measure of well-being. In their view the evidence points to the latter. The first option is not acceptable for Johns and Ormerod; as they say on p. 34 and 35: “...what would be the point of all those schools and hospitals? What would be the point of all these dedicated public servants? More public spending has not led to increases in happiness.” 
3. Johns and Ormerod also notice that self-reported happiness is based on different individual events and conditions. This makes it difficult to assess the impact of specific events and conditions. They conclude that ex-post analysis is therefore vulnerable to misinterpretations and manipulation. They fear that introducing the conclusions of happiness research in policy-decisions can produce unethical decisions and patronage. Marriage and religious faith have a positive impact on happiness and cultural heterogeneity has a negative impact. Such conclusions could justify the reduction of incentives for single parents, the promotion of religious faith and ethnic cleansing (p. 48, 70).

4. Johns and Ormerod find that revealed or stated individual preferences should never be overruled by conclusions about self-reported happiness. Referring to Kahneman (2002) and Smith (2002) they admit (p. 26) that people do not act as if they were maximising their utility by problems like bounded rationality and lack of information (Akerlof, 2002). They admit that economics need different postulates on individual behaviour from the conventional one of utility maximisation (p. 27). In that context they appreciate happiness-research as a useful part of the modern research program in economics. But happiness research suggests that individual preferences are not fixed and this is a bridge too far for Johns and Ormerod; as they say on page 27: “ ... once preferences are allowed to vary over time, the postulate that individuals take the best possible decision given their preferences loses much of its meaning”. They obviously fear that this could lead to a lack of respect for the individual free will. As they put it on page 68: "In fact, given that government policy appraisal already does include environmental and other non-market benefits, the dichotomy that the use of well-being research throws up is not that of a holistic versus a materialistic conception of welfare, rather it is between accepting individual preferences as a reasonable indicator of welfare and not doing so".

5. Johns and Ormerod prefer GNP as a better measure for average welfare and wellbeing. First of all because it is based on individual preferences, but also because GNPresearch has an established tradition and a good record of reliable and informative results (p. 59). The idea that GNP needs to be supplemented by some measure of 'gross national happiness' is in their view similar to arguments for modifying GNP to account for negative effects not incorporated in prices (externalities). How such an indicator would actually produce better decisions is, in their view, rarely spelt out in detail (p. 14). They believe there is no need for such additional measures of wellbeing.

\section{Comments}

\section{Happiness is not insensitive and rising around the world}

Johns and Ormerod's argument that self-reported happiness in nations is stable and insensitive is not in line with empirical data. As demonstrated by Veenhoven and Hagerty (2006), and Inglehart, Foa, Peterson and Welzel (2008) there are fluctuations in self-reported happiness and there is a general upward trend. According to data from the World Values Surveys people in most nations are happier than before. During the past 26 years the World Values Surveys have asked people how happy they are, using the same two questions: "Taking all things together, would you say you are very happy, rather happy, not very happy, not at all happy" And: “All things considered, how satisfied are you with your life as a whole these days?”. Combining the answers to these two questions, Inglehart and colleagues constructed an index of subjective well-being that reflects both happiness and general life satisfaction. In the 52 nations for which substantial time series are available from 1981 to 2007, this index rose in 40 
nations and fell in only 12. The average percentage of people who said they were "very happy" increased by almost seven points. Economic growth, democratization and rising social tolerance have contributed to this rising happiness.

Sensitive and rising, but what about an upper limit?

Self-reported happiness probably has an upper limit, obviously not because popular scales have limited categories, but in reality. Emotions are essential for happiness and can be very positive or negative, but not unlimited in either direction. In as far as happiness is cognitive there are other barriers: our ideas about our best and worst possible life. Such ideas always depend on knowledge about actual possibilities with limited variety. The existence of a theoretical maximum opens up the possibility that individuals and nations achieve maximum happiness in reality. Will self-reported happiness become insensitive to positive developments, once this maximum is reached? Perhaps it is like the Olympic Games: the records become sharper and breaking records will require more efforts. But it will be possible and the games will continue! In terms of every-day life and sheer logic however, Johns and Ormerod might have a point: if happiness is at its maximum it becomes insensitive to positive developments, even if such developments are deeply appreciated by large numbers of citizens. For the time being it is not a serious handicap. Most individuals and nations are not at their maximum, and even if they are it will be informative to compare them in cross-sectional analysis with individuals and nations at lower levels.

\section{Experience-sampling will support the analysis of self-reported happiness}

It is important to make a distinction between two types of subjective well-being. Self-reported happiness is about the appreciation of life as a whole, based on the ex post evaluation of many different positive and negative events and conditions. Reporting such happiness requires some cognitive reflection and is therefore influenced by complicated mechanisms, like social comparison. The analysis of such ex post self-reported happiness is therefore complicated indeed. Daily emotions and moods, on the other hand, are spontaneous and directly connected to immediate events and conditions. Such emotional experiences are assessed in experiencesampling, as described by Csikzentmihalyi and Hunter (2003). Brain-research (MRI) is an interesting new development in this field. Experience-sampling is promising because it can identify the relationships between specific situations and emotions. Experience-sampling can also produce a better understanding of the relationship between emotions and self-reported happiness. Daniel Kahneman has formulated one way to start this job: measuring "objective happiness" in a relevant period by assessing "subjective happiness" or instant utility at different moments within that period (Kahneman, 2003). It will take time and money, but there is no reason for pessimism! Johns and Ormerod overlook this important distinction between the analysis of self-reported happiness and experience-sampling. As a consequence they underestimate the potential support for self-reported happiness-research by experiencesampling. Before we continue this evaluation of self-reported happiness, as an indicator for average well-being, we consider revealed and stated preferences as alternative indicators.

\section{Revealed and stated preferences, exit and voice!}

Revealed preferences are preferences revealed in actual decisions and behaviour. Revealed preferences, in particular in economic decisions, are the dominant source of information in economics. GNP is interpreted as the actualisation of revealed preferences, as expressed in market-prices. Revealed preferences are informative about actual choices people make, their behaviour on markets, and their real priorities. A problem is the fact that revealed preferences 
depend on the actual supply of goods and services, the knowledge and disposable budgets of consumers, the honesty of producers, and the transparency of markets in general.

Stated preferences are the opinions people express about issues in general, but not necessarily issues they have to deal with in practice. Stated preferences speak for themselves and need relatively little additional interpretation and analysis. They are, therefore, the least vulnerable to manipulation. The weakness of stated preferences is that they also depend on the knowledge of respondents and that they are not binding: people can say whatever they like without personal consequences. A vote in free elections is a specific type of a stated preference.

The distinction between revealed and stated preferences is very similar to the distinction between two "feed-back-mechanisms", made by A. Hirschman (1972): "exit" and "voice". People can react in two ways if they have complaints about anything: they can refuse it and/or choose something else, or they can communicate their complaints to the people who are responsible for the things of which they disapprove. Both mechanisms are useful for everybody, including managers, politicians, policy-makers, employers, shop-keepers, and (ex-)husbands!

Pros and cons of self-reported happiness, compared to revealed and stated preferences Now we can summarize the most prominent pros and cons of self-reported happiness compared to revealed or stated preferences, as indicators for average well-being. Self-reported happiness is in particular informative about the actual impact on happiness of general conditions, like economic growth, democracy, tolerance, trust, governance, economic freedom and gender equality. The analysis of self-reported happiness is complicated since happiness is indeed affected by many different conditions. This complexity is a disadvantage compared to stated preferences about specific options, because the analysis of such stated preferences is relatively simple. It is however not a disadvantage compared to preferences revealed in actual behaviour, because the interpretation and analysis of such behaviour is equally complicated. For this reason stated preferences are the least vulnerable for manipulation. One practical point: collecting information about happiness and stated preferences is relatively cheap, since it can be done by asking rather simple questions. Collecting information about revealed preferences -by national statistical agencies- is more complicated and expensive. In a nutshell: research of revealed preferences is important because it is about actual behaviour, but it is complicated and expensive; research of self-reported happiness is complicated but cheap; research of stated preferences is simple ánd cheap, but stated preferences depend on knowledge just like revealed preferences, and they are non-committal. Self-reported happiness has therefore one important advantage compared to stated ánd revealed preferences: it is not dependent on the knowledge of people about specific options or about the conditions that make them happy. This is important because people have only limited knowledge of the conditions that make them happy, as has been nicely demonstrated by Gilbert in his "Stumbling on Happiness" (Gilbert 2007). For short: all indicators have specific advantages and additional value. Coming back to Johns and Ormerod: their book is somewhat unbalanced because they are very critical about the authenticity and complexity of self-reported happiness and not critical enough about of the authenticity and complexity of revealed and stated preferences.

Do we need self-reported happiness as an indicator for well-being, in addition to GNP? It follows from the discussion of pros and cons that GNP, stated preferences and self reported happiness have their own specific merits. All have additional value and combinations produce synergistic effects. The fact that GNP-research has a more established tradition, and so far perhaps a better record of reliable results, cannot change this conclusion. We might even go 
one step further. If we consider the aggregated value of goods and services in market prices as the only determinant of well-being, then we only need GNP as an indicator for well-being. But most economists, Johns and Ormerod included, accept the existence of "externalities", determinants of well-being which are not properly incorporated in market-prices and GNP. For that reason economists should appreciate the analysis of self-reported happiness as an option to identify such determinants and measure their impact. Economists should, in other words, appreciate the analysis of self-reported happiness as an option to assess the nature and magnitude of the "externalities" within their own discipline!

Akerlof, G.A. (1970) The market for "lemons": quality uncertainty and the market mechanism. Quarterly Journal of Economics, Vol. 84 (3): 488-500.

Csikzentmihalyi, M.; Hunter, J. (2003) Happiness in Everyday Life: The uses of Experience Sampling. Journal of Happiness Studies Vol. 4 nr. 2; p. 185-199.

Easterlin, R.A. (1974). Does Economic growth improve the human lot? In: P.A. David and M.W. Reder (eds), Nations and Households in Economic Growth: Essays in Honor of Moses Abramovitz, New York, Academic Press.

Gilbert, D.; Stumbling on Happiness; Vintage Books, Random House, New York 2007. Hirschman, A.O.(1970) Exit, Voice and Loyalty, Responses to Decline in Firms, Organizations and States, Harvard University Press ; Cambridge MA.

Inglehart, R.; Foa, R.; Peterson C.; Weltzel C. (2008) Development, Freedom, and Rising Happiness: A Global Perspective (1981-2007). Perspective on Psychological Science Vol. 3, issue 4, p. 264-285.

Irwin, F. (1944) The realism of expectations. Psychological Review 51, p. 120-126.

Kahneman, D. (1999) Objective Happiness in: Well-being; The Foundations of Hedonic Psychology. Edited by Kahneman, D.; Diener, E.; Schwarz, N.; Russell Sage Foundation, New York

Kahneman, D.; Maps of bounded rationality. Nobel Prize lecture, available at www.nobelprize.org/nobel_prizes/economics/laureates/2002/kahneman-lecture-html Smith, V.L.; Constructivist and ecological rationality in economics. Nobel Prize lecture, available at www.sd-research.org.uk/wellbeing/documents/FinalWellbeingPolicyBriefing.pdf Veenhoven, R.; Hagerty, M. (2006). Rising happiness in nations 1946-2004. A reply to Easterlin. Social Indicators Research, Vol. 79, 421-436. 